\title{
In-Vitro Sorbent-Mediated Removal of Edoxaban from Human Plasma and Albumin Solution
}

\author{
Alexandra A. Angheloiu ${ }^{1} \cdot$ Yanglan $\operatorname{Tan}^{2,3} \cdot$ Cristian Ruse $^{4} \cdot$ Scott A. Shaffer ${ }^{2,3} \cdot$ George O. Angheloiu $^{5}(0$
}

Published online: 15 May 2020

(c) The Author(s) 2020

\begin{abstract}
Background and Objective Based on previous experience of sorbent-mediated ticagrelor, dabigatran, and radiocontrast agent removal, we set out in this study to test the effect of two sorbents on the removal of edoxaban, a factor Xa antagonist direct oral anticoagulant.

Methods We circulated $100 \mathrm{~mL}$ of edoxaban solution during six first-pass cycles through 40-mL sorbent columns (containing either CytoSorb in three passes or Porapak Q 50-80 mesh in the remaining three passes) during experiments using human plasma and $4 \%$ bovine serum albumin solution as drug vehicles. Drug concentration was measured by liquid chromatographytandem mass spectrometry.

Results Edoxaban concentration in two experiments performed with human plasma dropped from 276.8 to $2.7 \mathrm{ng} / \mathrm{mL}$ and undetectable concentrations, respectively, with CytoSorb or Porapak Q 50-80 mesh $(p=0.0031)$. The average edoxaban concentration decreased from $407 \mathrm{ng} / \mathrm{mL} \pm 216 \mathrm{ng} / \mathrm{mL}$ to $3.3 \mathrm{ng} / \mathrm{mL} \pm 7 \mathrm{ng} / \mathrm{mL}(p=0.017)$, for a removal rate of $99 \%$ across all six samples of human plasma (two samples) and bovine serum albumin solution (four samples). In four out of the six adsorbed samples, the drug concentrations were undetectable.

Conclusion Sorbent-mediated technology may represent a viable pathway for edoxaban removal from human plasma or albumin solution.
\end{abstract}

\section{Key Points}

Porapak Q 50-80 mesh and CytoSorb are two sorbents that remove $99 \%$ of edoxaban from human plasma and bovine serum albumin solutions.

In several samples, the adsorbed edoxaban concentration was non-detectable.

In our set of experiments, we achieved complete removal in a minimum of $15 \mathrm{~min}$.

Electronic supplementary material The online version of this article (https://doi.org/10.1007/s40268-020-00308-1) contains supplementary material, which is available to authorized users.

George O. Angheloiu

angheloiug@upmc.edu; angheloiu1@yahoo.com

Temple University, Philadelphia, PA, USA

2 Mass Spectrometry Facility, University of Massachusetts Medical School, Shrewsbury, MA, USA

\section{Introduction}

The American Heart Association estimates that at least 6.1 million Americans are currently diagnosed on a yearly basis with atrial fibrillation [1]. A novel class of anticoagulants currently widely used in patients with atrial fibrillation are factor Xa antagonists, such as edoxaban. This article demonstrates a sorbent methodology of edoxaban removal from human plasma and bovine serum albumin (BSA), as an alternative to edoxaban antidotes [2].

Edoxaban is a novel anticoagulant acting reversibly on factor Xa with a clinical half-life of approximately 10-14 h and has been demonstrated to be non-inferior to warfarin in protecting against strokes or systemic embolism in patients with atrial fibrillation [3]. In the venous thromboembolism treatment Hokusai-VTE trial comparing edoxaban with

3 Biochemistry and Molecular Pharmacology, University of Massachusetts Medical School, Worcester, MA, USA

4 New England Biolabs, Ipswich, MA, USA

5 Cardiology Department, University of Pittsburgh Medical Center, 700 High Street, Williamsport, PA 17701, USA 
warfarin, the rate of major or clinically relevant non-major bleeding was $8.5 \%$ with edoxaban vs $10.3 \%$ for warfarin ( $p=0.004$ for superiority) [4].

Based on previous experience of sorbent-mediated ticagrelor, dabigatran, and radiocontrast agent removal, we set out in this study to test the effect of two sorbents, CytoSorb and Porapak Q 50-80 mesh on the removal of edoxaban from human plasma and 4\% BSA solution [5-9]. Our investigation does not intend to compare the adsorptive capacity of the two sorbents but merely to prove that removing edoxaban is a property of the sorbent family.

\section{Methods}

\subsection{Definitions}

Drug removal is the ratio expressed as a percentage of the difference between the affluent concentration (baseline) and the effluent concentration (adsorbed) divided by the affluent concentration. The filtration velocity expressed as output in $\mathrm{mL} / \mathrm{min}$ represents the velocity of the fluid vehicle (human plasma or BSA solution) carrying the drug through the sorbent column.

\subsection{Vehicle Solutions}

A stock edoxaban solution was obtained by mixing pure edoxaban powder (donated by Daiichi Sankyo, Nihonbashi, Tokyo, Japan) with 4\% BSA solution in normal saline, generating a concentration of $100 \mu \mathrm{g} / \mathrm{mL}$ of edoxaban. Human plasma was obtained from blood donated by a healthy volunteer in sodium citrate vacutainers and centrifuged at $5600 \mathrm{rpm}$ for $5 \mathrm{~min}$. Plasma was separated and frozen at $-20{ }^{\circ} \mathrm{C}$ between collection and experiments. The final adsorbed samples were frozen at $-80^{\circ} \mathrm{C}$ until concentration measurements were performed, and shipped in dry ice to the mass spectrometry laboratory.

Human plasma and 4\% BSA baseline solution with an edoxaban target concentration of $100 \mathrm{ng} / \mathrm{mL}$ (higher than $48.5 \mathrm{ng} / \mathrm{mL}$, the mean therapeutic concentration of edoxaban in patients allocated to the dose of $60 \mathrm{mg} /$ day in the ENGAGE atrial fibrillation trial) was generated prior to experiments by mixing the stock solution with human plasma or $4 \%$ BSA. A local institutional review board exemption was obtained for completing the study.

\subsection{System}

We studied edoxaban removal by CytoSorb (Cytosorbents, Monmouth Junction, NJ, USA) and Porapak Q 50-80 mesh (Supelco, Bellefonte, PA, USA) in a first-pass manner (injected from a syringe and then collected in a jar without recirculating the vehicle solution; Fig. 1). Each sorbent was injected during three first-pass trials. One hundred milliliters of solution were manually injected into the two types of sorbents' columns using $60-\mathrm{mL}$ volume syringes and clear plastic tubing. We used medical-grade tubing and syringes and thus did not expect any edoxaban adsorption from them. The drug-vehicle solution mix was circulated through the columns in an anti-gravitational fashion.

\subsection{First-Pass Experiments}

There were a total of six first passes performed by passing the effluent solution through $40 \mathrm{~mL}$ of sorbent. We used increasing filtration velocities at increasingly shorter experimental adsorption times, to assess the minimum necessary adsorption time.

Two trials used human plasma as a vehicle by passing the drug-plasma mix through the two types of sorbents for $30 \mathrm{~min}$ (velocity $3.3 \mathrm{~mL} / \mathrm{min}$ ). Four passes used BSA-edoxaban (two passes for each sorbent). In two BSA-edoxaban experiments, the drug-vehicle mix was passed for a duration of $15 \mathrm{~min}$ through the two types of sorbents and in two other passes for $60 \mathrm{~min}$ (at velocities of 6.7 and $1.7 \mathrm{~mL} / \mathrm{min}$, respectively).

\subsubsection{Edoxaban Concentration Measurement Assay}

Edoxaban concentration was assessed using liquid chromatography-tandem mass spectrometry.

\subsubsection{Sample Preparation}

A stock solution of edoxaban was prepared in methanol at concentrations of $1.00 \mathrm{mg} / \mathrm{mL}$. Serial dilutions were made with blank 4\% BSA to prepare calibrated standard solutions at the concentrations of $0.5-800 \mathrm{ng} / \mathrm{mL}$. The internal

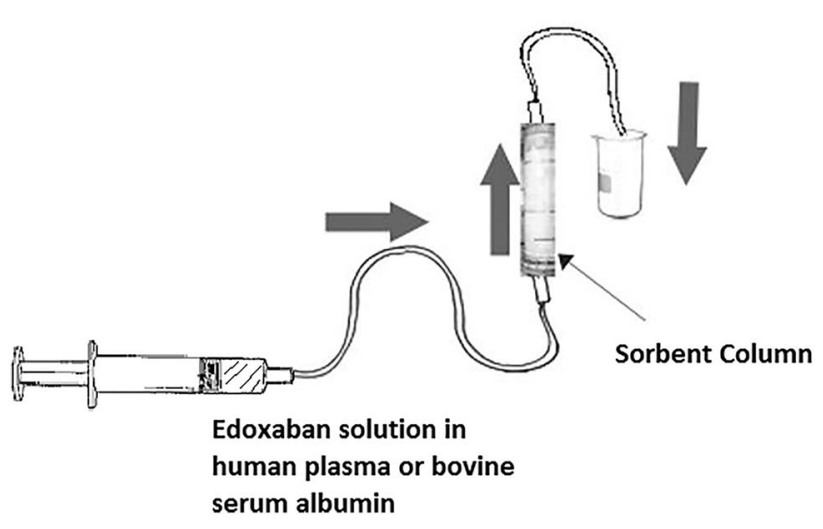

Fig. 1 Experimental set-up 
standard solution was prepared using diazepam in methanol/ water $(1: 1, \mathrm{v}: \mathrm{v})$ at a diazepam concentration of $100 \mathrm{ng} / \mathrm{mL}$.

Calibration samples were prepared in duplicate by mixing $50 \mu \mathrm{L}$ of each calibrate standard solution and $10 \mu \mathrm{L}$ of internal standard solution. After adding $150 \mu \mathrm{L}$ of acetonitrile containing $1.0 \%(\mathrm{v} / \mathrm{v})$ formic acid and vortexing for $1 \mathrm{~min}$, the samples were centrifuged $(16,000 \mathrm{~g}, 10 \mathrm{~min})$ and $100 \mu \mathrm{L}$ of supernatant was collected for liquid chromatography-tandem mass spectrometry analysis. Study samples were also prepared in duplicate by following the procedures above.

\subsubsection{Liquid Chromatography-Tandem Mass Spectrometry Analysis}

Two microliters of samples were injected into a Thermo Scientific Ultimate 3000 HPLC system coupled with a Thermo Scientific TSQ Quantiva triple quadrupole mass spectrometer. The chromatographic separation was performed on a Waters Acquity BEH C18 column $(1.7 \mu \mathrm{m}, 2.1 \times 100 \mathrm{~mm})$. The column oven temperature was maintained at $25^{\circ} \mathrm{C}$. The mobile phase consisted of water containing $0.1 \%$ formic acid (A) and acetonitrile (B) and pumped at a flow rate of $0.25 \mathrm{~mL} / \mathrm{min}$. The gradient conditions were set as follows: $0 \mathrm{~min}, 20 \% \mathrm{~B}$, $1.0 \mathrm{~min}, 20 \% \mathrm{~B}, 6.0 \mathrm{~min}, 95 \% \mathrm{~B}, 10.0 \mathrm{~min}, 95 \% \mathrm{~B}, 10.1 \mathrm{~min}$, $20 \%$ B, 15.0 min, $20 \%$ B, giving a total 15-min run.

Ionization was operated in the positive mode (voltage, $3.8 \mathrm{kV}$ ). The parameters were set as follows: sheath gas, $40 \mathrm{Arb}$; aux gas, $15 \mathrm{Arb}$; vaporizer temperature, $250{ }^{\circ} \mathrm{C}$; ion transfer tube temperature, $325^{\circ} \mathrm{C}$. Multiple reaction monitoring was performed using a cycle time of $0.3 \mathrm{~s}$, CID gas pressure of 1.5 mTorr, Q1 resolution (full width at half maximum) of 0.7 and Q3 resolution (full width at half maximum) of 0.7. The multiple reaction monitoring transitions, $m / z 548.2>366.1$ (CE $18.4 \mathrm{~V}$ ) for edoxaban and $\mathrm{m} / \mathrm{z}$ $285.1>193.1$ (CE 31.4 V) for diazepam were selected and used for quantitation.

\subsubsection{Data Analysis}

The retention times for edoxaban and diazepam were $3.7 \mathrm{~min}$ and $5.4 \mathrm{~min}$, respectively. All data were integrated and processed in Xcalibur (Version 2.2; Thermo Scientific, San Jose, CA). Edoxaban was quantified based on the peak area ratio to diazepam. Calibration curves were constructed by plotting the peak area ratios as a function of concentration. Origin was excluded and a $1 / X^{2}$ axis weighting was applied. A good linear dynamic range was obtained between 0.5 and $800 \mathrm{ng} / \mathrm{mL}$, and the detection limit was $0.1 \mathrm{ng} / \mathrm{mL}$.

\subsubsection{Statistics}

Mean values were compared using the paired Student $t$ test, using a Microsoft Office 2016 Excel spreadsheet.

\section{Results}

The average baseline concentration of edoxaban in the six samples of human plasma and BSA solution was $407 \pm 216 \mathrm{ng} / \mathrm{mL}$ with a drop to a value of $3.3 \pm 7 \mathrm{ng} / \mathrm{mL}$ after adsorption ( $p=0.006$; Fig. 2a; Table 1$)$. The baseline average concentration in the human plasma samples was $276.8 \mathrm{ng} / \mathrm{mL}$. After adsorption, the concentration in human plasma dropped to $1.35 \pm 1.9 \mathrm{ng} / \mathrm{mL}(p=0.003$; Fig. $2 \mathrm{~b}$; Table 1).

The rate of edoxaban removal was $99.5 \%$ in human plasma and 99\% across all six samples (Fig. 3). The average baseline concentrations with Porapak Q 50-80 mesh and CytoSorb were $490 \pm 185 \mathrm{ng} / \mathrm{mL}$ and $325 \pm 251 \mathrm{ng} / \mathrm{mL}$ while the adsorbed values were $0 \mathrm{ng} / \mathrm{mL}$ and $6.7 \pm 9 \mathrm{ng} / \mathrm{mL}$, respectively ( $p<0.001$ for both comparisons; Table 1$)$.

The shortest run lasted $15 \mathrm{~min}$. In this experiment we succeeded to decrease the edoxaban concentration from $593.6 \mathrm{ng} / \mathrm{mL}$ to non-detectable concentrations and $17 \mathrm{ng} /$ $\mathrm{mL}$, with removal rates of $100 \%$ for Porapak Q 50-80 mesh and $97 \%$ for CytoSorb repectively.

\section{Discussion}

Edoxaban was non-inferior to warfarin in the ENGAGE AFTIMI trial with respect to the prevention of stroke or systemic embolism and was associated with significantly lower rates of bleeding and death from cardiovascular causes [3]. While the yearly risk of major bleeding was higher with warfarin (3.43\%), the bleeding risk with a high dose of $60 \mathrm{mg} /$ day of edoxaban $(2.75 \%)$ was not insignificant [1].

We presented in this study an efficient method to remove edoxaban both from human plasma and 4\% BSA solution in a series of six bench experiments. In human plasma experiments, the drug average concentration decreased from 276.8 to $1.4 \mathrm{ng} / \mathrm{mL}$ (Fig. 2b), for a removal rate of $99.5 \%$ ( $p=0.0031$; Fig. 3 ). We were able to decrease the average concentration in the pooled series of samples from $407 \mathrm{ng} /$ $\mathrm{mL} \pm 216 \mathrm{ng} / \mathrm{mL}$ to $3.3 \mathrm{ng} / \mathrm{mL} \pm 7 \mathrm{ng} / \mathrm{mL}$ (Fig. $2 \mathrm{a}$ ).

\subsection{Clinical Significance}

The average baseline edoxaban concentration in the human plasma and pooled samples (276.8 and $407 \mathrm{ng} / \mathrm{mL}$ ) was higher than the highest mean concentration of $48.5 \mathrm{ng} / \mathrm{mL}$ corresponding to the $60-\mathrm{mg} /$ day dose used in ENGAGE AF-TIMI, and comparable to the peak plasma concentration of $256 \mathrm{ng} / \mathrm{mL}$ after one oral $60-\mathrm{mg}$ dose [9, 10]. The adsorbed final concentrations were much lower than these values [10]. All adsorbed edoxaban concentrations obtained with Porapak Q 50-80 mesh and those resulting 


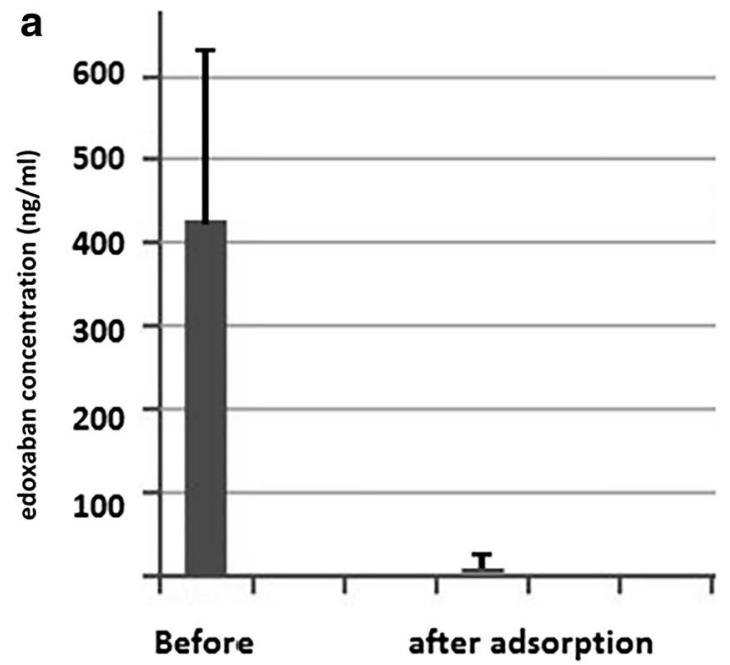

Fig. 2 Concentration of edoxaban in the six samples of human plasma (two samples) and bovine serum albumin (BSA) solution (four samples) as measured by liquid chromatography-tandem

Table 1 Baseline and adsorbed edoxaban concentrations in two samples of human plasma (column 1), across all six samples (column 2), and in samples passed through Porapak Q 50-80 mesh (column 3) and CytoSorb (column 4)

\begin{tabular}{cllll}
\hline & $\begin{array}{c}\text { Human } \\
\text { plasma }\end{array}$ & All samples & $\begin{array}{l}\text { Porapak Q } \\
50-80\end{array}$ & CytoSorbb \\
\hline $\begin{array}{c}\text { Baseline } \\
\text { concen- } \\
\text { tration } \\
(\text { ng/mL) }\end{array}$ & 276.8 & $407 \pm 216$ & $490 \pm 185$ & $325 \pm 251$ \\
$\begin{array}{c}\text { Adsorbed } \\
\text { concen- } \\
\text { tration } \\
(\text { ng/mL) }\end{array}$ & $1.4 \pm 1.9$ & $3.3 \pm 7$ & 0 & \\
$P$ value & 0.003 & 0.01 & $<0.001$ & $<0.001$ \\
\hline
\end{tabular}

from 60-min CytoSorb removal were undetectable, hence they were lower than the half maximal inhibitory concentration for anti-Xa activity of edoxaban of $3 \mathrm{nM}$ or $1.6 \mathrm{ng} /$ $\mathrm{mL}[10]$.

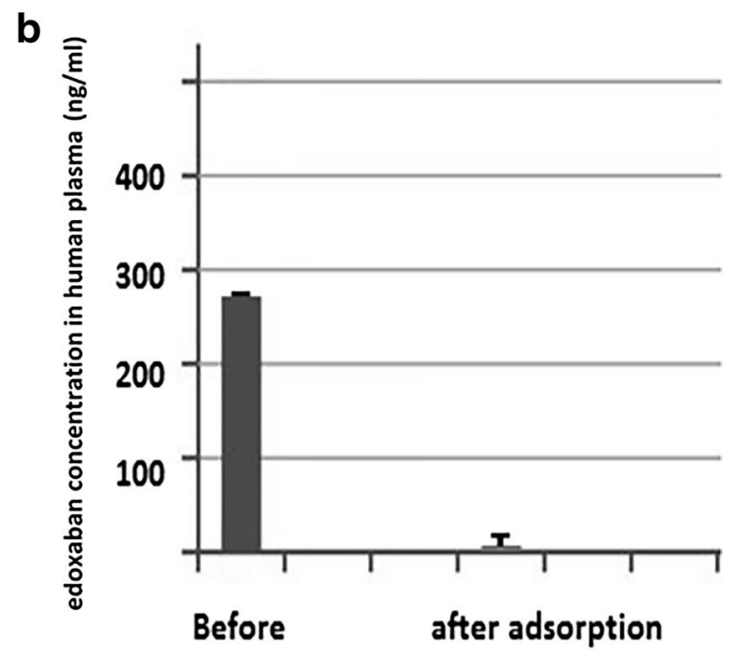

mass spectrometry before (baseline concentration) and after sorbent adsorption (adsorbed concentration) (a); average concentration of edoxaban in human plasma before and after sorbent adsorption (b)

Both sorbents showed excellent removal capacity even with very short circulating times. While running the firstpass circuit for only $15 \mathrm{~min}$, we obtained removal rates of $100 \%$ in 4\% BSA for Porapak Q 50-80 mesh and 97\% for CytoSorb (average 99\%), succeeding to decrease the edoxaban concentration from $593.6 \mathrm{ng} / \mathrm{mL}$ to non-detectable concentrations and $17 \mathrm{ng} / \mathrm{mL}$, respectively. As we obtained 99\% removal with high velocities, it is possible that similar removal rates can be obtained with even shorter circulation times.

We recently achieved excellent results in sorbent removal of antiplatelet medications such as ticagrelor, direct thrombin inhibitor anticoagulants such as dabigatran, as well as radiocontrast agents commonly used in cardiac catheterization procedures [5-8]. Our current findings along with previously presented results may allow sorbent technology to become an important tool in avoiding or treating important side effects of agents commonly used in day-by-day clinical cardiology work.
Fig. 3 Average removal rate of edoxaban across all six samples (a), in human plasma [two samples (b)] and comparatively CytoSorb for three samples and Porapak Q 50-80 mesh column for the remaining three samples (c)

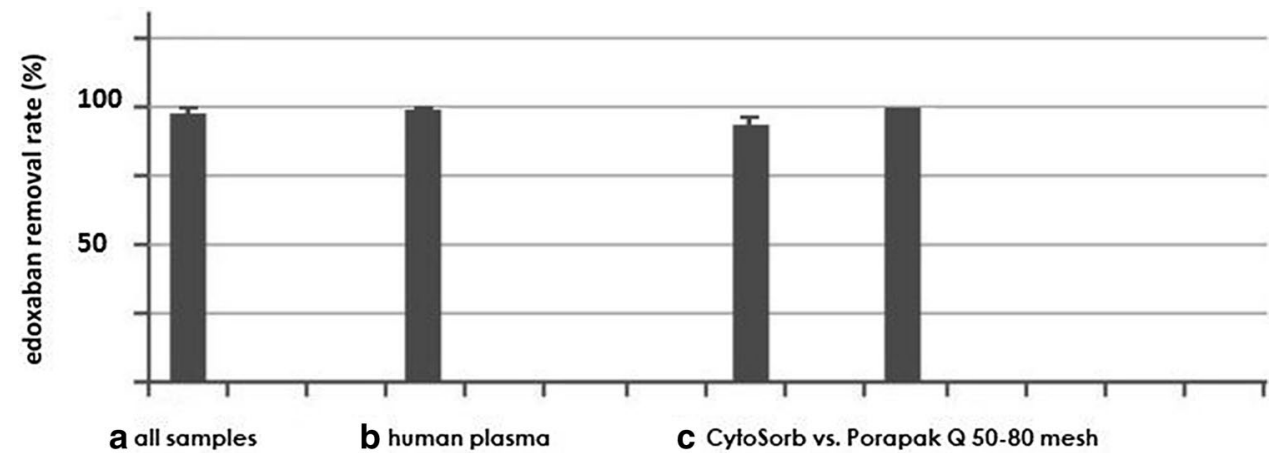


Sorbents, such as Porapak Q 50-80 mesh and CytoSorb, are widely used in the industry and the household environment (most recognizable in potable water filtration). They are styrene copolymers beads with a small diameter and a large adsorption surface per bead $\left(550 \mathrm{~m}^{2} / \mathrm{g}\right.$ and $850 \mathrm{~m}^{2} / \mathrm{g}$, respectively), rich in carbon and hydrogen molecules. It is being theorized that they interact with the other carbon and hydrogen atoms from molecules such as edoxaban, dabigatran, or radiocontrast agents through hydrophobic van der Waals and hydrogen bonds [5]. CytoSorb has obtained the European Union approval for removal of cytokines during cardiopulmonary bypass in coronary artery bypass graft surgery [11].

One can imagine removing edoxaban clinically by means of hemadsorption (blood is passed directly through the sorbent column) or hemodiadsorption, where hemodialysis is complemented by sorbent technology. In the latter scenario, the dialysate fluid is circulated and cleaned through the sorbent while being pushed through the sorbent column by the dialysis machine pump, with no need of significant additional hardware.

Regarding the intra-venous access needed, one can use a central large-bore double-lumen catheter similar with a dialysis catheter or a central intra-venous line (internal jugular, subclavian, or femoral). Alternatively, one can employ a double-lumen, peripherally inserted central catheter. The latter may accommodate a $40-\mathrm{mL} / \mathrm{min}$ one-way suction output. In general, a venous access can result in minor blood extravasation in anticoagulated patients but no significant hemorrhagic complications unless the operator cannulates by mistake an arterial conduit.

Patients could be simultaneously taking both antiplatelet and anticoagulant agents, such as during treatment for atrial fibrillation and coronary disease. As our method can remove both edoxaban and the P2Y12 antagonist ticagrelor, the hemadsorption route would be the most suitable in the case of a hemorrhage caused by this drug combination, where one could fit the patients with a dual lumen central line that would transfer that patient's venous blood to and from a hemadsorption machine. A second clinical scenario where hemadsorption could be used is the possibility of removing the two drugs prior and during open-heart surgery, where blood is being circulated through a cardiopulmonary bypass machine, which would allow one to pass the former through a sorbent column. In a third but similar scenario, of vascular surgery, the blood is usually bypassed through a shunt to avoid bleeding in the area served by the artery operated on. The shunted blood can be directed to a sorbent column before being sent back to the patient.

We used 4\% BSA solution because this value is similar to the physiologic albumin concentration. Fifty-five percent of edoxaban in plasma binds to proteins of which albumin is the major component. The remaining proteins, mostly globulins, interact with drugs through similar forces as albumin, hence we assumed in this experiment that BSA solution would behave in a similar manner as a mixture of albumin and globulins, allowing us to pool together the human plasma and BSA samples in some of our calculations.

It is important to note that sorbents can remove through hydrophobic bonds other drugs used in atrial fibrillation such as heart rate control agents, including beta-blockers or calcium channel blockers, [12] eventually resulting in the need to temporarily increase the dose of these two classes of drugs during the short adsorption process. Dialysis removes low quantities of edoxaban and ticagrelor [5, 7, 13, 14], likely because there is no active mechanism of retaining a drug with hemodialysis but just a passive equilibrium of the two sides separated by the dialysis membrane. Sorbent adsorption may have an advantage in this respect likely owing to the active mechanism of drug retention through van der Waals and hydrogen bonds [5].

While our study has investigated only edoxaban, a clinical trial using CytoSorb showed improved outcomes in a population of patients treated with ticagrelor or rivaroxaban and then undergoing sorbent-based drug removal during coronary artery bypass graft surgery [15], suggesting that hemadsorption could be used in a large portion of patients treated with factor Xa antagonists. In summary, sorbentmediated edoxaban removal has the potential of improving the clinical outcome or shortening the length of stay in patients anticoagulated with this agent and admitted with a hemorrhage or waiting to undergo urgent open-heart or vascular surgery.

\subsection{Anti-Xa Antidote Methods Tested Elsewhere}

As an alternative to removal procedures, andexanet alfa and ciraparantag are two factor Xa inhibitor antagonists in various stages of clinical and preclinical trials [2]. None of these drugs are directed against other types of anticoagulants or antiplatelet and radiocontrast agents [2]. In addition to these shortcomings, andexanet alfa tends to be expensive (between US $\$ 29,700$ and US $\$ 59,400$ for a treatment) and presents an $18 \%$ risk of thrombosis [16]. An alternative is the prothrombin complex concentrate product, which may be used off-label for the treatment of life-threatening hemorrhaging and costs US\$9695 per treatment [16]. While no good analysis has been published to our knowledge for hemadsorption, one may eventually extrapolate its cost from hemodialysis data. Hemodialysis in a Medicare patient would cost approximately US $\$ 9726 /$ month or roughly US $\$ 810 /$ session in the first year of dialysis [17]. To this amount, one may add the current cost of the sorbent at US $\$ 1000$ for a $300-\mathrm{mL}$ cartridge (CytoSorbents, data on file), to a total of US\$1810, considerably lower than the cost of any of the two options 
listed above. In the scenario where one uses a hemodiadsorption system, no additional hardware might be needed in addition to the dialysis machine as detailed previously. If a different machine might be needed for regular hemadsorption sessions, one may need to factor in the cost of that particular equipment.

\subsection{Limitations}

We used low velocities with the purpose of achieving optimal removal targets in this first edoxaban removal study. By increasing the sorbent volume and adsorption velocity, we could reach in future studies faster removal times, possibly with a minor drop in the current removal rate values.

The discrepancy between the baseline target concentration of $100 \mathrm{ng} / \mathrm{mL}$ and resulting baseline values of $407 \pm 216 \mathrm{ng} /$ $\mathrm{mL}$ (baseline average of all six samples) and $276.8 \mathrm{ng} / \mathrm{mL}$ (average of baseline human plasma) was likely a result of possible inconsistencies during the steps of weighing and diluting from a bulk sample of $8 \mathrm{mg}$ of edoxaban. Nonetheless, these baseline values are higher than the target $100 \mathrm{ng} / \mathrm{mL}$, offering a plus in the process of demonstrating the potency of our edoxaban sorbent removal method.

We used a relatively low number of samples. Further experiments may be needed to confirm our results. On the same note, further in-vivo studies will need to assess the return to an eventual normal coagulation status after edoxaban removal.

\section{Conclusions}

Sorbents are efficient tools for robustly removing edoxaban during fast first-pass bench experiments using human plasma and BSA solutions.

Acknowledgments We kindly acknowledge the technical support of Yevgeniy (Jim) Krol, Marlen Casabona-Rojas, Lisa Batchelor, Peter Ishak, and Brian Baker (all from Daiichi Sankyo), Viorel Arhire, and Kyrstin Hubbard, and greatly appreciate the help of the laboratory personnel at the University of Pittsburgh Medical Center Williamsport for blood collection and processing.

\section{Compliance with Ethical Standards}

Conflict of interest Alexandra A. Angheloiu, Yanglan Tan, Cristian Ruse, Scott A. Shaffer, and George O. Angheloiu have no conflicts of interest that are directly relevant to the content of this article.

Funding A study Grant was awarded by Daiichi Sankyo towards the completion of this study.

Open Access This article is licensed under a Creative Commons Attribution-NonCommercial 4.0 International License, which permits any non-commercial use, sharing, adaptation, distribution and reproduction in any medium or format, as long as you give appropriate credit to the original author(s) and the source, provide a link to the Creative Commons licence, and indicate if changes were made. The images or other third party material in this article are included in the article's Creative Commons licence, unless indicated otherwise in a credit line to the material. If material is not included in the article's Creative Commons licence and your intended use is not permitted by statutory regulation or exceeds the permitted use, you will need to obtain permission directly from the copyright holder.To view a copy of this licence, visit http://creativecommons.org/licenses/by-nc/4.0/.

\section{References}

1. Williams BA, Honushefsky AM, Berger PB. Temporal trends in the incidence, prevalence, and survival of patients with atrial fibrillation from 2004 to 2016. Am J Cardiol. 2017;120:1961-5.

2. Connolly SJ, Milling TJ Jr, Eikelboom JW, Gibson CM, Curnutte JT, Gold A, ANNEXA-4 Investigators, et al. Andexanet alfa for acute major bleeding associated with factor Xa inhibitors. N Engl J Med. 2016;375:1131-41.

3. Giugliano RP, Ruff CT, Braunwald E, Murphy SA, Wiviott SD, Halperin JL, ENGAGE AF-TIMI 48 Investigators, et al. Edoxaban versus warfarin in patients with atrial fibrillation. N Engl J Med. 2013;369:2093-104.

4. Hokusai-VTE Investigators, Büller HR, Décousus H, Grosso MA, Mercuri M, Middeldorp S, Prins MH, et al. Edoxaban versus warfarin for the treatment of symptomatic venous thromboembolism. N Engl J Med. 2013;369:1406-15.

5. Angheloiu GO, Gugiu BG, Ruse C, Pandey R, Dasari RR, Whatling C. Ticagrelor removal from human blood. JACC Basic Transl Sci. 2017;2:135-45.

6. Angheloiu GO, Hänscheid H, Wen X, Capponi V, Anderson WD, Kellum JA. Experimental first-pass method for testing and comparing sorbent polymers used in the clearance of iodine contrast materials. Blood Purif. 2012;34:34-9.

7. Angheloiu AA, Angheloiu GO. Removal of dabigatran using sorbent hemadsorption. Int J Cardiol. 2019;293:73-5.

8. Angheloiu GO, Hänscheid H, Reiners C, Anderson WD, Kellum JA. In vitro catheter and sorbent-based method for clearance of radiocontrast material during cerebral interventions. Cardiovasc Revasc Med. 2013;14:207-12.

9. Ruff CT, Giugliano RP, Braunwald E, Morrow DA, Murphy SA, Kuder JF, et al. Association between edoxaban dose, concentration, anti-factor Xa activity, and outcomes: an analysis of data from the randomised, double-blind ENGAGE AF-TIMI 48 trial. Lancet. 2015;385:2288-95.

10. Parasrampuria DA, Truitt KE. Pharmacokinetics and pharmacodynamics of edoxaban, a non-vitamin $\mathrm{K}$ antagonist oral anticoagulant that inhibits clotting factor Xa. Clin Pharmacokinet. 2016;55:641-55.

11. Bernardi MH, Rinoesl H, Dragosits K, Ristl R, Hoffelner F, Opfermann $\mathrm{P}$, et al. Effect of hemoadsorption during cardiopulmonary bypass surgery: a blinded, randomized, controlled pilot study using a novel adsorbent. Crit Care. 2016;9(20):96.

12. Mangani F, Luck G, Fraudeau C, Vérette E. On-line columnswitching high-performance liquid chromatography analysis of cardiovascular drugs in serum with automated sample clean-up and zone-cutting technique to perform chiral separation. J Chromatogr A. 1997;762:235-41.

13. Parasrampuria DA, Marbury T, Matsushima N, Chen S, Wickremasingha $\mathrm{PK}$, He L, et al. Pharmacokinetics, safety, and tolerability of edoxaban in end-stage renal disease subjects undergoing haemodialysis. Thromb Haemost. 2015;113:719-27. 
14. Khadzhynov D, Wagner F, Formella S, et al. Effective elimination of dabigatran by haemodialysis: a phase I single-centre study in patients with end-stage renal disease. Thromb Haemost. 2013;109:596-605.

15. Hassan K, Kannmacher J, Wohlmuth P, Budde U, Schmoeckel $\mathrm{M}$, Geidel S. Cytosorb adsorption during emergency cardiac operations in patients at high risk of bleeding. Ann Thorac Surg. 2019;108:45-51.

16. Carpenter E, Singh D, Dietrich E, Gums J. Andexanet alfa for reversal of factor Xa inhibitor-associated anticoagulation. Ther Adv Drug Saf. 2019;26:1-12. 